\title{
Augmented reality mobile application for museum: a technology acceptance study
}

\begin{abstract}
The tourism sector in Malaysia is reported for losing its global competitiveness when the nation missed its tourism targets recently. Mirrored at the state level, the tourism performance of Melaka, a heritage city inscribed by the UNESCO, is also experiencing similar downward trend. The museums, which play a pivotal role in showcasing the local culture and history, have seen decreasing number of visitors. Inspired by Tourism 4.0, many museums are now using digital technologies to enrich visitors' experience, such as augmented reality (AR). This is because the tourists are now becoming more tech-savvy and expecting culture and heritage to be presented lively rather than exhibited in dusty glass boxes. In the "When History Comes Alive" Project, an AR mobile app was developed for the People's Museum in Melaka. Although tourism studies have widely discussed the managerial implications of AR, user's acceptance of AR in the tourism context is still in its infancy. Hence, this study aimed to examine the factors affecting museum visitors' behavioural intention to use the AR mobile app. A survey was conducted among 120 museum visitors. The findings showed that playfulness expectancy, content relevance expectancy, performance expectancy, effort expectancy, and social influence positively affect the respondents' behavioural intention to use the AR mobile app with a high explanatory power of $61.2 \%$. Significant managerial and practical implications to the developers of AR mobile app, tourism businesses and policy makers are highlighted in this paper. The limitations of the study and suggestions for future studies are also addressed.
\end{abstract}

Keyword: Tourism 4.0; Augmented reality; Cultural and heritage tourism; User's acceptance; UTAUT 